\title{
Knowledge Management Processes and Organisational Effectiveness in Nigerian Deposit Money Banks
}

\author{
Adudu, Chiangi Adudu ${ }^{1}$ \\ Indyer, Gideon Terlumun ${ }^{2}$ \\ Belagu, Imo Terkaa ${ }^{3}$ \\ Yaba College of Technology, Nigeria ${ }^{1,3}$ \\ University of Lagos, Nigeria ${ }^{2}$
}

\begin{abstract}
The main objective of the study was to examine the effect of knowledge management processes on organisational effectiveness in Nigerian deposit money banks. Specifically, the study examines knowledge creation, acquisition, sharing and storage and organisational effectiveness in Nigerian deposit money banks. The data for the study was generated through a questionnaire which yielded 359 valid responses and was determined scientifically using Krejcie \& Morgan (1970) from selected Nigerian deposit money banks with their operational head offices in Lagos-Nigeria as the population of the study. The study adopted survey design and the validity results of KMO, and Bartletts test indicate that variables are highly significant, and principal component analysis was suitable (.837). The test-retest result of reliability reported a reliability index of 0.872 . Multiple regressions with the aid of SPSS version 21 were used to test the formulated hypotheses. Findings of the study show that knowledge creation (32.3\%), acquisition $(62.1 \%)$, sharing (42.4\%), and storage $(46.2 \%)$ have a positive significant effect on organisational effectiveness. The study recommends among others that management of Nigerian deposit money banks should aptly designed and encourage knowledge processes in their banks since it constitutes a valuable intangible asset for creating and sustaining exceptional competitive advantages in the Nigerian banking industry.
\end{abstract}

Keywords: Deposit Money Banks, Organisational Effectiveness, Knowledge Management Processes

*Corresponding author: Adudu, Chiangi Adudu; Email: aduduson4@gmail.com DOI: https://doi.org/10.37227/IJEKM-2021-03-119

\section{Introduction}

The idea of knowledge management was established as management and information system discipline since 1991. Knowledge management has emerged as one of the most popular and new management techniques. One of the most debated areas of knowledge management is the association between knowledge and overall firm performance. Past studies are available on the relationship, but lack of understanding and consensus remains a major issue. The modern era is commonly understood as the information age. Bennet and Bennet (2001), argue that organisations have always used knowledge, but the new intense focus on knowledge in organisations has risen out of the organisations need to manage 
their own growing complexity and yet remain competitive. Organisations have long been creating, storing, integrating, tailoring, and making available the right knowledge because it is knowledge that creates a sustainable advantage; but in today's world, the knowledge skill is becoming the skill to master. This era will be seen as one where a shift occurred from the Weberian bureaucratic paradigm to the information-based paradigm. What will this new paradigm require of those within organisations? Drucker (2001), believes that organisations, and their managers need to develop new skills to face and meet challenges within this new age. The new challenges will be centered on functioning within an information-based organisation and managers will have to focus on knowledge growth, transfer, and implementation. Drucker (2001) picks up on a paradigm change within organisational life, the shift from production-based organisations to information-based organisations. Managers now need to have the ability to manage knowledge. Managers need to develop personal leadership strategies and new organisational structures to facilitate knowledge growth and transfer.

Knowledge management is an important aspect in every organisation and the practice of capturing and developing individual and collective knowledge in an organisation. Implementing knowledge management enables the organisation in becoming more flexible and better at responding to intense global competition. Implementing Knowledge management allows knowledge to be shared among the employees who will eventually lead to organisational effectiveness and gaining competitive advantages. Nowadays, decisive drivers for firm practices and performance are the differences in the firm's knowledge bases and capabilities of using and developing knowledge. The pioneering academic discussion addressing the phenomenon revolved mainly around the concept of knowledge management by (Nonaka and Takeuchi, 1995). Knowledge management is representing the processes and practices conducted in the firm with the aim of unleashing its intellectual potentials by improving the effectiveness and efficiency of the management of organisational knowledge resources (Heisig, 2009).

Knowledge management, being a key strategy for future organisation as future society is touted to be society of knowledge (Wu et. al. 2011). Knowledge management involves complicated process and activities that create, identify, share, and adjust the organisations knowledge (Nonaka, 1994). Again, knowledge management is an important strategy which can improve organisation competitiveness and performance as the implementation of knowledge will lead the organisation in becoming more adaptive, innovative, intelligent, and sustainable (Nurul-Huda, 2007). With the rapid development in the knowledge-based economy, knowledge is considered an important measure to create prosperity and success (Abubakar et al., 2019). Researchers like Santoro et al. (2018) explained that capacity as the organisation's ability to value, integrate, and apply new knowledge for improving organisational performance. In the current era of a knowledgebased economy, knowledge plays an important role in driving the value of an organization. Individuals with valued knowledge help to achieve and extend the organisational performance that ultimately contributes to the sustainability of the organizations (Ha and Lo, 2018).

Knowledge management helps organizations to manage the organizational arteries better as increased exchanges of information between different individuals results in greater connectivity and more network effects (Liebowitz, 1999; Abubakar et al., 2019). In other words, knowledge management systems help in managing innovation and organisational learning. This is a direct and beneficial effect of knowledge management 
and one, which is driving more and more companies to have working and efficient knowledge management systems (Liebowitz, 1999). It is no longer the case that having a knowledge management system is a luxury or an afterthought. Indeed, the business landscape is now characterised by companies that leverage human capital and knowledge capital and hence, a knowledge management system is necessary for any large organisation.

Consequently, the value of knowledge management processes is not restricted to employees of the Nigerian deposit money banks but also resulting to organisational effectiveness in Nigerian deposit money banks. Several studies have been carried out on knowledge management in developing economies with few concentrating on knowledge management processes and organisational effectiveness especially in the Nigerian deposit money banks. To fill this gap identified by literature, the current study investigates the effect of knowledge management processes and organisational effectiveness in Nigerian deposit money banks with reference to selected deposit money banks at their Headquarters in Lagos state, Nigeria. The findings of this study will be beneficial to management of Nigerian deposit money banks in providing and supporting knowledge management processes within their banks to enhance organisational effectiveness. The findings of this study will also add to the existing body of knowledge that will aid in understanding of knowledge management processes and its relevance to organisational effectiveness. The findings of this study will be of help to managers of deposit money banks and associated industries on the gains of proper knowledge management processes in their organizations. Finally, the findings of this study will serve as a source of reference materials for researchers, captains of industries as well as students who intend to carry out research on related topic.

The main objective of this study was to examine the effect of knowledge management processes and organisational effectiveness in Nigerian deposit money banks. The specific objectives of the study are to: Determine the effect of knowledge creation and organisational effectiveness in Nigerian deposit money banks. Investigate the effect of knowledge acquisition and organizational effectiveness in Nigerian deposit money banks. Assess the effect of knowledge sharing and organisational effectiveness in Nigerian deposit money banks. Investigate the effect of knowledge storage and organisational effectiveness in Nigerian deposit money banks.

\section{Literature Review}

Knowledge management processes are series of activities an organization put in place for the facilitation and use of knowledge. The management of knowledge is a continuous process in which one form of knowledge is transformed into the other. Knowledge management processes support the conversion of tacit knowledge to explicit knowledge and explicit to tacit. Many scholars such as Mutula \& Mooko (2008) entails capturing the knowledge that the employees and customers need at a central repository. Identification of the categories of knowledge needed to support the overall business strategy. Process of collecting, classifying, and disseminating information throughout the organization. Employment of information technology to help organize and store information, and provision of access tools. It refers to a multidisciplinary approach to achieve organisational objectives by making the best use of knowledge (Girard and Girard, 2015).

Knowledge management is the process of creating, sharing, using, and managing the knowledge and information of an organisation (Liebowitz, 1999; Islam, Jantan, Khan,

International Journal of Education and Knowledge Management (IJEKM) 
Rahman, \& Monshi, 2018). Knowledge management efforts have a long history, including on-the-job discussions, formal apprenticeship, discussion forums, corporate libraries, professional training, and mentoring programs (Sanchez, 1996). With increased use of computers in the second half of the 20th century, specific adaptations of technologies such as knowledge bases, expert systems, information repositories, group decision support systems, intranets, and computer-supported cooperative work have been introduced to further enhance such efforts. Many large companies, public institutions and non-profit organizations have resources dedicated to internal knowledge management efforts, often as a part of their business strategy, information technology, or human resource management departments. Several consulting companies provide advice regarding knowledge management to these organizations (Addicot, McGivern and Ferlie, 2006).

Knowledge management efforts typically focus on organisational objectives such as improved performance, competitive advantage, innovation, the sharing of lessons learned, integration and continuous improvement of the organisation (Gupta and Sharma, 2004). These efforts overlap with organisational learning and may be distinguished from that by a greater focus on the management of knowledge as a strategic asset and encouraging the sharing of knowledge. Knowledge management is an enabler of organisational learning (Maier, 2007). Knowledge management is the deliberate and systematic coordination of organizations' people, technology, processes, and organisational structure to add value through reuse and innovation. This is achieved through the promotion of creating, sharing, and applying knowledge as well as through the feeding of valuable lessons learned and best practices into corporate memory to foster continued organisational learning (Dalkir, 2005).

The crucial element in any knowledge management system is to ensure that tacit knowledge is captured and converted to explicit knowledge. Moreover, it has been hypothesized that even explicit knowledge needs to be converted into information that is meaningful and useful. After all, mere data is not useful and only when data is transformed into information and codified as knowledge that it becomes useful. There are different strategies to capture knowledge and they include the push and the pull strategies. First, it must be made clear that knowledge can be captured before, during, and after the processes are actualised. Hence, there is need to have incentives for employees to contribute to the knowledge base. The push strategy focuses on making employees contribute to the knowledge management system in a proactive manner wherein individuals strive to contribute to the knowledge management system and the knowledge base without any prodding or persuasion. This approach is also known as the codification approach to knowledge management. Another strategy is the pull strategy wherein individuals who need knowledge make explicit requests to those who possess knowledge. In this case, the experts are called upon request and hence the knowledge seeker pulls the information rather than the expert pushing the information. This approach is known as the personalisation approach to knowledge management.

There are several motivations that drive organizations to implement knowledge management processes and systems. The need to have knowledge management processes and system has become mandatory for certifications as well as to have sources of competitive advantage. The most compelling motivation for having a knowledge management process and system is that organisations do not have to reinvent the wheel and subsequent iterations of the same process can be done in a more efficient and productive manner. Indeed, the reuse of knowledge leads to synergies between the different processes 
and helps in solving intractable problems. The process of knowledge management processes involves knowledge acquisition, creation, refinement, storage, transfer, sharing and utilisation (King, 2009). (Igbinovia and Ikenwe, 2016) state that the processes of knowledge management with knowledge acquisition and generation, knowledge chapter, knowledge organisation, knowledge storage, knowledge sharing, and knowledge application and the goal of all knowledge management processes are to create new knowledge and manage the old ones as well.

\section{Knowledge Management Processes}

Knowledge management processes is defined as all the activities that are conducted on knowledge by relative authorities, individually and collectively inside and outside the organization. Processes in knowledge management refer to all essential and sub activities on knowledge with the nature of said processes differing from one organisation to another. There is no agreement among researchers about the number of knowledge management process. However, this study adopted some of the knowledge management processes outlined by King (2009), Igbinovia and Ikenwe (2016) and Umogbai (2021).

\section{Knowledge Creation}

The creation and management of knowledge has become a central concern to business and management, both as a source of value and as an opportunity to achieve and sustain competitive advantage. The ability to create new knowledge is often at the heart of the organisation's competitive advantage. Sometimes this issue is not treated as part of knowledge management since it borders and overlaps with innovation management (Wellman 2009). Knowledge creation according to the (Nonaka \& Takeuchi 1996). SECI model is about continuous transfer, combination, and conversion of the different types of knowledge, as users' practice, interact, and learn. Cook and Brown (1999), distinguish between knowledge and knowing and suggest that knowledge creation is a product of the interplay between them. The shift in condition between the possession of knowledge and the act of knowing something that comes about through practice, action, and interaction is the driving force in the creation of new knowledge.

Furthermore, for this interplay to be most fruitful, it is important to support unstructured work environments in areas where creativity and innovation are important. Knowledge sharing and knowledge creation thus, go hand in hand. Knowledge is created through practice, collaboration, interaction, and education, as the different knowledge types are shared and converted. Beyond this, knowledge creation is also supported by relevant information and data which can improve decisions and serve as building blocks in the creation of new knowledge (Hossain, Islam \& Haque, 2021). In conclusion, knowledge creation depends upon the mechanisms described in the subsection on knowledge sharing, combined with the ability to put knowledge into practice in an environment which supports interaction and experimentation. The creative process is a delicate one, and it is easily ruined by strict adherence to rules and regulations, or by bureaucracy.

\section{Knowledge Acquisition}

Knowledge acquisition is the process used to define the rules and ontologies required for a knowledge-based system. The phrase was first used in conjunction with expert systems to describe the initial tasks associated with developing an expert system, namely finding and interviewing domain experts and capturing their knowledge via rules, objects, and frame- 
based ontologies. Expert systems were one of the first successful applications of artificial intelligence technology to real world business problems. Researchers at Stanford and other AI laboratories worked with doctors and other highly skilled experts to develop systems that could automate complex tasks such as medical diagnosis. Until this point, computers had mostly been used to highly automate data intensive tasks but not for complex reasoning. Technologies such as inference engines allowed developers for the first time to tackle more complex problems (Russell and Norvig, 1995). Knowledge acquisition is a method of learning, first proposed by Aristotle in his seminal work "Organon". Aristotle proposed that the mind at birth is a blank slate, or tabula rasa. As a blank slate it contains no knowledge of the objective, empirical universe, nor of itself. Knowledge acquisition is the process of extracting, structuring, and organising knowledge from one source, usually human experts, so it can be used in software such as an Expert System. This is often the major obstacle in building an Expert System. As a method, it is opposed to the concept of "a priori" knowledge, and to "intuition" when conceived as religious revelation. It has been suggested that the mind is "hard wired" to begin operating at birth, beginning a lifetime process of acquisition through abstraction, induction, and conception.

Knowledge sharing: Knowledge sharing is an activity through which knowledge is exchanged among people, friends, peers, families, communities, or within or between organizations. Knowledge sharing is part of the knowledge management process. Knowledge sharing is an activity through which knowledge (namely, information, skills, or expertise) is exchanged among people, friends, peers, families, communities (Wikipedia), or within or between organizations. Knowledge sharing is part of the knowledge management process (Dalkir, 2005). People share knowledge through many channels such as conversations, meetings, learning sessions, workshops, videos, and other communication media. Organisations have recognised that knowledge constitutes a valuable intangible asset for creating and sustaining competitive advantages (Miller and Shamsie, 1996). Knowledge sharing activities are generally supported by knowledge management systems. However, technology constitutes only one of the many factors that affect the sharing of knowledge in organizations, such as organizational culture, (trust, and incentives. sharing of knowledge constitutes a major challenge in the field of knowledge management because some employees tend to resist sharing their knowledge with the rest of the organization. In the digital world, websites and applications enable knowledge or talent sharing between individuals and /or within teams.

The individuals can easily reach the people who want to learn and share their talent to get rewarded. Sharing knowledge is an intentional process that not only bolsters an individual's understanding but helps create or enhance an archive of accessible knowledge for others. The concept of knowledge sharing is important because it helps individuals and businesses to be more agile and adaptable in the face of change and helps ensure continued growth and survival. Knowledge sharing capacity assists in problem-solving, adopting new technology, creating an invention, and enhancing the dynamic capabilities of an organization (Ali et al., 2019). Therefore, knowledge management is not enough to enhance performance until considering knowledge sharing as a dynamic capability in relation to entrepreneurial and organisational performance (Rafique et al., 2018).

\section{Knowledge Storage}

Knowledge storage is the process of holding knowledge for later retrieval. Stored knowledge, often called organisational memory, includes knowledge that employees recall 
as well as knowledge embedded in the organisations systems and structures. One way of retaining the organisations memory is motivating employees to remain with the company. A second organisational memory strategy is to systematically transfer knowledge to other employees. This occurs when newcomers apprentice with skilled employees, thereby acquiring knowledge that is not documented. A third strategy is to document knowledge that was previously hidden in the minds of individual employees. This is where the knowledge will be stored. Much of it today is stored in paper-based documents, such as books and manuals. However, this makes it hard to update and distribute. Paper based storage systems also lack dynamic storage systems. For example, a youngster's toy car collection can be categorised in several ways to suit his or her needs, while a manual is generally organised by chapters and key words. Moore's Law holds that the maximum processing power of a microchip at a given price doubles roughly every 18 months. In other words, computers become faster, but the price of a given level of computing power halves, which gives computers their organising power (Marzano, 1998).

\section{Organizational Effectiveness}

Erkuttu and Chafra (2006), looked at organisational effectiveness as a concept which explains the optimal utilisation of resources by combining the effort of employees and the organisation itself. The manufacturing organisations to Nayak and Misha (2005), Ali et al. (2011), Martz (2013), and Jain (2017), are linked with many measurable variables but critical among them are productivity, profitability, and growth. In their views, manufacturing organisation may have gain competitive advantage, higher profit margin and monopolise a larger and a larger share of the market. Organisational effectiveness, therefore, describes the degree to which a corporate entity achieves its set target. Organisation effectiveness refers to how well an organisation can access the essential resources and achieves their objectives via core strategies (Suhaida, 2012). According to Zook (2015), organisational effectiveness describes organisation purpose, by providing important decision-making information, highlighting organisation supports, demonstrate impact, increase accountability, and enhance researcher understanding. It also leads to organisation, building their strategy and practice. Furthermore, organisational effectiveness also helps the organisation to align its mission to be incorporated in its operations and actions. Zheng (2005) suggests that organisational effectiveness allows organisation to understand its goals. The measure of effectiveness can be dependent on the customers perceptions on the organisation, such as customer satisfaction, employee relation, business process, learning and growth, and profitability. The mission of an organisation is to achieve highest level of organisational effectiveness, and this is reflected by the organisations social, technical system, culture, structure, and strategies, which are the main factors in reaching greater effectiveness.

\section{Dimensions of Organisational Effectiveness}

\section{Organisational Growth}

Organisational opportunities are highly related to its current organisational production activities which also impact on the growth. Organisational growth has the potential to provide small businesses with a myriad of benefits, including things like greater efficiencies from economies of scale, increased power, a greater ability to withstand market fluctuations, an increased survival rate, greater profits, and increased prestige for 
organisational members. Many small firms desire growth because it is seen generally as a sign of success and progress. Organisational growth is, in fact, used as one indicator of effectiveness for small businesses and it is a fundamental concern of many practicing managers. Organisation growth is manifested through increase in the number of employees income, profit, or market share (Witek-Crabb, 2014). The viability of growth in an organisation is high and unpredictable. They went further to state that even though growth is highly unpredictable in an organisation, organisations can achieve growth through different ways since one single growth indicator cannot measure multidimensional growth. Organisational growth, however, means different things to different organizations. There are many parameters a company may use to measure its growth. Since the goal of most companies is profitability, most companies will measure their growth in terms of net profit, revenue, and other financial data. Other business owners may use one of the following criteria for assessing their growth: sales, number of employees, physical expansion, success of a product line, or increased market share. Ultimately, success and growth will be gauged by how well a firm does relative to the goals it has set for itself. To Delmar, David, and Gartner (2003), the viability of growth in an organisation is high and unpredictable. From the above literature review, an organisation that is experiencing growth must have been or is making profit since efficiency and effectiveness in an organization also result in growth or expansion of the organization.

\section{Operational Efficiency}

Kalluru and Bhat (2009) define operational efficiency as the proficiency of a corporation to curtail the unwelcome and maximize resource capabilities to deliver quality products and services to customers. An organisational operational efficiency depends on factors like skillful and proficient workers, proper technological progression, proper procurement carried out, return to scale of the businesses, supply chain controlling among many others. Operational efficiency is used as a measure of non-financial performance as outlined by, Kamanga and Ismail (2016) and they aver that operational efficiency leads to improved productivity and consequently profitability as compared to other non-financial performance measures (Ndolo, 2015). Operational efficiency is suitable in the organizations because, the key to create value and achieve competitive edge among banks lies in the better operational efficiency and productivity (Kalluru and Bhat, 2009; Bhagavath, 2009; Ndolo, 2015).

Adudu, Asenge and Torough (2020), argue that improving operational efficiency begins with measuring it. Since operational efficiency is about the output to input ratio, it must be measured on both the input and output side. Quite often, company's management is measured primarily on the input side, e.g., the unit production cost or the man hours required to produce one unit. Even though important, input indicators like the unit production cost should not be seen as sole indicators of operational efficiency. When measuring operational efficiency, a company should define, measure, and track a few performance indicators on both the input and output side. The exact definition of these performance indicators varies between industries, but typically covers input and output (Adudu, Asenge and Torough (2020). From the literature above, an organization that curtails the unwelcome and maximise resource capabilities to deliver quality products and services to customers to maximise profits, growth and even productivity. 


\section{Profitability}

Profitability is the state of producing a profit in an organisation or business or the degree to which a business or organization is profitable which is the primary goal for all business venture (Amah, 2006). To Nongo (2011), profitability can be defined as either accounting profit or economic profit. Accounting profit of an organisation is evaluated by comparing the amount of capital employed into the input with income or the output of the organisation. This is popularly known as return on investment or return on capital employed. To Adudu, Asenge and Torough (2020), profitability means the ability of a business to make profit and remain sustainable. It indicates and measures the success of the business. Profitability of an organisation is an important financial indicator to reflect the efficiency of the organisation and the owners/managers ability to increase sales while keeping the variable costs down (Davis et al. 2000). The net profit or income is an indicator of the firms' profitable operations, which is the surplus of total revenues over total expenses during the accounting year. The firm may be unprofitable if the total expenses are more than total revenues, known as net loss. Profit margin, return on assets, return on equity, return on investment, and return on sales are the common measures of financial profitability (Adudu, Asenge and Torough 2020). Profitability ratios such as gross profit margin (GPM), net profit margin (NPM), operating expense ratio (OER), return on investment (ROI), return on equity (ROE), earnings per share (EPS), dividend per share (DPS), dividend payout ratio (DPR), dividend yield (DY) and earnings yield (EY), price earning ration $(\mathrm{P} / \mathrm{E})$ are used in measuring profitability of the firm (Pandey, 2010).

Accounting profit provides the viability of the organisation which the consistent losses amount to failure of the organisation. The economic profits can be measured by relating output as a proportion of input or matching it with results of the other organisations of the same industry or results attained in the different periods of operations. Economic profits give a long-term perspective of an organisation which provides opportunities to owners of an organisation to make comparisons in terms of their investment and other organisations (Dewua, Ogaga and Agber, 2021). Profitability is a criterion for organisational effectiveness since its parameters show how well an organisation is doing. Martz (2013) is of the view that profitability may be expressed in terms of net income, earnings per share or return on investment which is measured using profitability. Profitability ratios are used to assess the financial performance of an organisation when compared to the standard or scale set by the organisation towards attainment of its objectives. From the above discussions, profitability measure shows the extent to which the organization is effective towards attainment of organisational set goals and objectives. Profit can also be the yardstick for judging not just the economic activities, but the managerial efficiency and social objectives of an organisation.

\section{Organizational Commitment}

Organisational commitment is defined as a view of an organisation's members psychology towards his/her attachment to the organisation that he/she is working for. Organisational commitment plays a pivotal role in determining whether an employee will stay with the organization for a longer period and work passionately towards achieving the organization's goal. If an organisational commitment is determined, it helps predict employee satisfaction, employee engagement, distribution of leadership, job performance, job insecurity, and similar such attributes. An employee's level of commitment towards his 
/ her work is important to know from a managements point of view to be able to know their dedication to the tasks assigned to them daily.

Organisational scientists have also developed many nuanced definitions of organisational commitment, and numerous scales to measure them. Exemplary of this work is Meyer and Allen (1991) model of commitment, which was developed to integrate numerous definitions of commitment that had been proliferated in the literature. Meyer and Allen (1991) model have also been critiqued because the model is not consistent with empirical findings. It may also not be fully applicable in domains such as customer behaviour. There has also been debate surrounding what Meyers and Allen (1991) model was trying to achieve. The basis behind many of these studies was to find ways to improve how workers feel about their jobs so that these workers would become more committed to their organizations. Organizational commitment predicts work variables such as turnover, organisational citizenship behaviour, and job performance. Some of the factors such as role stress, empowerment, job insecurity and employability, and distribution of leadership have been shown to be connected to a worker's sense of organisational commitment. From the discussions above, the benefits and advantages of organisational commitment is that organisational commitment determines how long employees stay with an organisation, committed employees are any and every organisation asset. Some of the key benefits and advantages of organisational commitment are high employee productivity, reduced absenteeism, excellent team players and strong advocates.

\section{Theoretical Review}

The knowledge-based theory of the firm considers knowledge as the most strategically significant resource of a firm. Its proponents argue that because knowledge-based resources are usually difficult to imitate and socially complex, heterogeneous knowledge bases and capabilities among firms are the major determinants of sustained competitive advantage and superior corporate performance. This knowledge is embedded and carried through multiple entities including organisational culture and identity, policies, routines, documents, systems, and employees. Originating from the strategic management literature, this perspective builds upon and extends the resource-based view of the firm (RBV) initially promoted by Penrose (1959) and later expanded by others (Wernerfelt, 1984, Barney 1991, Conner 1991).

Although the resource-based view of the firm recognises the important role of knowledge in firms that achieve a competitive advantage, proponents of the knowledgebased view argue that the resource-based perspective does not go far enough. Specifically, the resource-based view treats knowledge as a generic resource, rather than having special characteristics. It, therefore, does not distinguish between different types of knowledgebased capabilities. Information technologies can play an important role in the knowledgebased view of the firm in that information systems can be used to synthesize, enhance, and expedite large-scale intra- and inter-firm knowledge management (Alavi and Leidner 2001). Whether or not the Knowledge-based theory of the firm constitutes a theory has been the subject of considerable debate.

The theory is considered suitable in this study due to its relevance as it constitutes a crucial element of competitive advantage and its ability to integrates the tacit knowledge of individuals in a specialised manner and helps in managing structures in organisations. Organisations are heterogeneous and considered as social entities of which the deposit money banks are and have the capabilities and competencies for growth, survival, and 
success. To Ode (2021), knowledge assets are complex, however when firms successfully integrate and align these intangible assets, innovation can be achieved. To Nonaka (1994), knowledge is a multifaceted concept with multi-layered meanings.

\section{Empirical Review}

Kharabsheh, Magableh and Sawadha (2012), in their study of knowledge management practices and its impact on organisational performance in pharmaceutical firms in Jordan argue about the importance of knowledge management as a valuable instrument in improving performance. They also emphasise on effectiveness and ability of an organisation to implement knowledge-based activities to determine the development and sustainability of its competitive advantage. The study uses survey questionnaire and multiple regression method for data analysis. A sample of thirteen pharmaceutical firms was used. The finding of the study reported a significant and positive association between Knowledge management practices and organisational performance. The study is relevant by directing and beaming search light on knowledge management in the pharmaceutical firms even though the area of interest in the two studies differs.

Byukusenge, Munene and Orobia (2016), examine the mediating effect of innovation in the relationship between knowledge management and business performance of SMEs in Rwanda. A cross-sectional survey and quantitative methodological approach were used to collect data used to carry out mediation test. The study results revealed that innovation had a positive effect on business performance. However, there was no direct effect of knowledge management on business performance, except through the full mediation of innovation. This implies that without innovation, Rwandan SMEs may not achieve an improved business performance. This study contributes to existing body of knowledge management on the improvement of business performance of SMEs through innovation. The results could help business owners to make use of the available knowledge resources by transforming them into new products, new processes, and new markets to boost their business performance. This study used a cross sectional research design and was limited to investigate the effect of knowledge management and innovation on business performance.

Al-Emrana et al. (2018) examined knowledge management processes on information systems systematically and sheds the light on knowledge management processes studies related to information systems aiming to provide a comprehensive analysis of 41 research articles published in peer-reviewed journals from 2001 to 2018. The main findings of this study indicate that knowledge sharing is the most frequent knowledge management process studied, followed by knowledge acquisition and knowledge application. Besides, questionnaire surveys were found to be the primarily relied on research methods for data collection in the context of knowledge management processes. In addition, $78 \%$ of the analyzed studies registered positive research outcomes. In terms of information systems type, most of the analyzed studies focused on investigating the impact of knowledge management processes on E-business systems, knowledge management systems, and information systems outsourcing, respectively. This study beams its search light on information systems while the current study is on the banking industry.

Zaim, Mohammed, and Tarim (2018), examines the relationship between knowledge management processes and its impact on knowledge management performance. A structural model of knowledge management processes showing the relationship of 
knowledge generation, knowledge sharing, knowledge storage, and knowledge utilization and its subsequent impact on organisational KM performance is proposed. The model is tested using data collected from 1068 individuals working in primarily service-based organisations in Turkey. A split-sample methodology is used to validate our measurement model and to further test the structural model. The results indicate that knowledge utilisation mediates the relationship between rest of the knowledge management processes and organisational knowledge management performance. Knowledge generation is found to directly impact knowledge management performance, in addition to having a mediated impact through knowledge utilisation. The results also provide support for the hypothesized relationship that suggests that the impact of knowledge generation and knowledge sharing on knowledge utilisation is mediated by knowledge capture. The study is in line with the current study with some processes of knowledge management but differs in the dependent variable.

Abusweilem and Abualoush (2019), investigated the relationship between knowledge management in its operations; including knowledge generation, knowledge sharing, knowledge usage and business intelligence; including OLAP, data mining on the performance of organisations in the branches of the Housing Bank in Irbid, Jordan. A total of 126 questionnaires were distributed to the sample of the study. A multiple regression analysis was used to test the hypotheses of the study. The study concludes that there was a positive relationship between the knowledge management processes and the performance of organisations. Moreover, the components of business intelligence had positive impacts on the performance of organisations. The results have some enormous implications for the banking sector of Jordan. This study concentrates on relationship while the current study is an effect-oriented study.

Balasubramanian, Al-Ahbabi and Sreejith (2019) investigated the impact of ownership of public sector organizations on the implementation of knowledge management (KM) processes and subsequent performance. Using 268 responses obtained from a structured country-wide survey, the study assesses the hypothesized differences in the implementation of KM processes (knowledge creation, knowledge capture and storage, knowledge sharing and knowledge application and use), the overall performance benefits of implementation (innovation, quality, and operational performance), and their relationships, among the federal, state, and semi-government organizations in the United Arab Emirates. The results show that federal government organizations implement all four $\mathrm{KM}$ processes to the greatest extent, followed by state and semi-government organizations. In general, all KM processes had a significant positive impact on the innovation, quality, and operational performance of the public sector, but the strength of this impact was found to differ across different public sector organizations. The overall improvement in all three performance aspects was found to be highest for federal, followed by state and semigovernment organizations. The findings of this study are useful for practitioners and policymakers, especially those overseeing national KM programmes to devise strategies, policies, and support mechanisms to ensure that public sector organizations, regardless of their ownership, can implement efficient and effective KM processes and achieve their desired performance goals. This differs with the current study though of very important because it beam it search light to examine knowledge management processes in the public sector.

Samir (2020) examines the impact of knowledge management on SMEs Performance in Egypt using three-dimensional constructs: knowledge acquisition, 
knowledge sharing and knowledge application. While organisational performance was divided into two dimensions namely, non-financial performance and financial performance. The researcher chose non-financial performance which was conceptualized as three-dimensional constructs: innovativeness, competitive advantage, customer satisfaction. Based on this finding, the researcher revealed some important conclusions. Regarding the first objective, knowledge acquisition, knowledge sharing and knowledge application impact on Innovativeness are statistically significant positive effect, so the first hypothesis is fully supported. Concerning Knowledge Acquisition, Knowledge Sharing, Knowledge Application, and their relationship to Competitive Advantage. It was found that knowledge acquisition, knowledge sharing and knowledge application impact on Competitive Advantage are statistically significant positive effect, so the second hypothesis is fully supported. For the impact of Knowledge Management dimensions; Knowledge Acquisition, Knowledge Sharing, Knowledge Application, on Customer Satisfaction. It was found that the relationship is significant between Knowledge Acquisition, Knowledge Sharing, and Customer Satisfaction while Knowledge Application has an insignificant effect on Customer Satisfaction, so the third hypothesis is partially supported. Moreover, Firm Type as a moderator between knowledge management dimensions and performance dimensions was rejected. The current focuses on the banking industry while this study is tailored to SMEs.

Cardoni et al. (2020), explore the relationships between knowledge management $(\mathrm{KM})$, performance measurement systems (PMSs), and small and medium enterprises (SMEs) economic sustainability in knowledge-intensive sectors. The literature demonstrates that SMEs are often characterised by unstructured KM approaches and limited PMS implementation, sometimes affected by scarce profitability and financial issues. Adopting the knowledge-based view of the firm and the contingency theory of PMSs, we tested the impact of two alternative KM approaches (exploitation and exploration) on SMEs economic sustainability, measuring the moderating effect of PMS use (diagnostic and interactive). Through an ordinary least square (OLS) regression of data collected for 219 Italian medium firms operating in knowledge-intensive sectors. This study provides evidence on how a specific KM approach supports the SME economic sustainability and how a consistent implementation and use of PMS amplify the relationship between KM and economic sustainability. Data analysis confirms the relevance of some key concepts of the knowledge-based view of the firm, especially the positive impact of the KM exploration approach on economic sustainability. The study extends empirical evidence for the PMS moderating effect on the KM performance relationship. To the best of our knowledge, this is the first time that a study provides evidence for the relationships among KM, PMSs, and economic sustainability in the SME setting. Moreover, our findings lead to some managerial implications, especially they encourage SME entrepreneurs and managers to design a coherent $\mathrm{KM}$ approach and to implement an adequate PMS to support economic sustainability.

Umogbai (2021), examined the effect of knowledge management (knowledge creation, knowledge acquisition, knowledge sharing, knowledge storage and knowledge implementation) on the performance of the Nigerian banking industry. The study adopted a survey design method and questionnaire was used for data collection. The population of the study consists of 105 staff of the First bank branches in Makurdi metropolis and a census sampling method was adopted. Regression analysis was used for test of hypotheses at 0.05 significance level. Findings of the study revealed that knowledge creation 
significantly affects organisational performance in the Nigerian banking industry. Findings of the study revealed that knowledge acquisition significantly affects organisational performance in the Nigerian banking industry. Findings of the study revealed that knowledge sharing significantly affects organisational performance in the Nigerian banking industry. Findings of the study also revealed that there is a positive significant relationship between knowledge management and organisational performance in the Nigerian banking industry. Finally, the study established that a significant relationship exists between knowledge implementation and organisational performance in the Nigerian banking industry. The study concludes that knowledge management practices influence organisational performance. The study recommends amongst others that management should undertake inhouse trainings on knowledge management and entrench good practices of knowledge management in organizations to strengthen information sharing among staff. The findings of this study are relevant in Nigerian deposit money banks which is in line with the current study and its associated dimensions of knowledge management. However, the scope of these study differs since the current study focuses on the headquarters of this money deposit banks located in Lagos state, Nigeria. While the former focuses on branches of a deposit money bank in Makurdi metropolis.

Ode (2021) examines how Knowledge Management Strategies contributes to innovation in service firm from a developing country perspective. Specifically, the study examines knowledge management strategies (generation, transfer, storage, and application). The data for this study was generated through questionnaire which yielded 293 valid responses from service firms in Nigeria. This study adopted an exploratory research design and a drop-off-pick-up (DOPU) data collection technique. SPSS AMOS Version 20 was used to analyse the data using a covariance-based structured equation modelling (CB-SEM) approach. The results shows that knowledge management strategies influence firm innovation directly and indirectly as a hierarchy. The findings show that knowledge management strategies (application, storage, and generation) contribute to firm innovation, but in different ways. The findings show that knowledge generation, storage and transfer strategy demonstrate the highest effect on firm innovation through knowledge application strategy. The study dwells on strategies and focus on firm in the service industry like the current study but differs as compared to the current study's interest of knowledge management processes.

Cai, et al. (2021) investigated the influence of knowledge management practices on the entrepreneurial and organisational performance with the mediating effect of dynamic capabilities and moderating role of opportunity recognition. Data were gathered from 486 entrepreneurs and applied a structural equation model to test the hypotheses. We found that knowledge management practices have a positive and significant influence on dynamic capabilities, as well as have a significant impact on entrepreneurial and organizational performance. Moreover, results indicated that dynamic capabilities partially mediate in the relationship between knowledge management practices on entrepreneurial and organisational performance. Furthermore, the relationship between knowledge management practices with entrepreneurial and organisational performance strengthening by opportunity recognition. This study differs the current by incorporating the aspect of entrepreneurship.

Forouzan, Mohammad and Paria (2021) examines the mediating role of human capital in the relationship between knowledge management and performance of Kabul Steel Plant, which is the largest steel plant in Afghanistan. The research model was 
developed through the literature review. The initial data were collected through a questionnaire containing 48 questions. Participants were 108 managers and administrative staff of the company. The collected data were analyzed by using the SPSS and Smarts software. The hypotheses regarding the impact of strategy and technology on knowledge management were rejected by using correlation analysis and $t$-test statistic. Finally, the findings showed the positive effects of variables of structure, culture, leadership, and trust on knowledge management in an organization. Also, knowledge management influences the organizational performance, both directly and through the mediating variable of human capital. This research encourages the managers and employees of organizations to use the available organisational resources to implement knowledge management in organizations and improve knowledge management practices and human resources that are the most valuable resources of any organization to remain competitive in the markets. This study is about human involvement in knowledge management.

From the above review, there are limited empirical evidence on the phenomenon of interest on emerging market like Nigeria. This necessitated the current study to examine the effect of knowledge management processes on organisational effectiveness of Nigerian deposit money banks. Thus, the following hypotheses are formulated.

$\mathrm{H}_{01}$. Knowledge creation has no significance effect on organisational effectiveness in Nigerian deposit money banks.

$\mathrm{H}_{02}$. Knowledge acquisition has no significance effect on organisational effectiveness in Nigerian deposit money banks.

$\mathrm{H}_{3}$. Knowledge sharing has no significance effect on organisational effectiveness in Nigerian deposit money banks.

$\mathrm{H}_{04}$. Knowledge storage has no significance effect on organisational effectiveness in Nigerian deposit money banks.

\section{Research Methodology}

This study employs a survey design to collect data from the staff of selected Nigerian deposit money banks at their Headquarters in Lagos, Nigeria. The banking sector is important because it relies on knowledge management information systems to function effectively and efficiently. The banking in addition contributes a significant proportion to Nigeria's GDP by over $50 \%$. The banking sector being part of the service sector is considered in this study due to its innovation potentials and the nature of knowledge intensiveness.

\section{Population of the Study}

The population of this study consists of 5,445 employees of four (4) selected Nigerian deposit money banks which First bank plc and Union bank represent old generation banks. While Zenith bank and First city monument bank represent the new generation banks.

\section{Sample and Sample Techniques}

The sample size from the population of the study was computed scientifically, using Krejcie and Morgan (1970), formular as recommended by Biemer and Lyberg (2003). In this study, the acceptable amount of sampling error or precision is set at 0.05 or $5 \%$. The study adopted the simple random technique. Iacobucci (2010), recommends a sample of 200 as fair and 300 as good. Considering the challenges of survey methodology in 
developing countries which can lead to low response rates, this technique has the potentials of increasing the response rates because the researchers engage the respondents' multiple times, using physical visits and reminders. The equation provided below:

$$
\begin{array}{cc}
\mathrm{S}= & \mathrm{X}^{2} \mathrm{NP}(1-\mathrm{P}) \\
\alpha^{2}+(\mathrm{N}-1)+\mathrm{X}^{2} \mathrm{P}(1-\mathrm{P})
\end{array}
$$

Where:

$\mathrm{S}=$ Sample size

$\mathrm{X}^{2}=\mathrm{Z}$ Statistic value associated with the $95 \%$ confidence interval (1.96)

$\mathrm{N}=$ the population of the size

$\mathrm{P}=$ Population proportion assumed to be $(50 \%)$

The sample size of the participants who are employees of the selected Nigerian deposit money banks is computed as follows:

$$
\begin{gathered}
S=\quad(1.96) 2(5445)(0.50)(0.50) \\
(0.05) 2+(5445-1)+(1.96) 2(0.50)(0.50) \\
\quad S=359
\end{gathered}
$$

Simple random sampling technique was used in the selection of the respondents. This technique, every member of the population has equal chances of being selected to participate in the survey.

\section{Instrumentation}

Primary data were collected through a structured questionnaire distributed to staff of Nigerian deposit money banks at their various headquarters in Lagos, Nigeria. The research derived measures for key constructs from existing scales in the literature. The questionnaire contains closed-ended questions developed on five-point Likert Scale measurements as follows: Strongly disagree (1), Disagree (2), Undecided (3), Agree (4), and strongly agree (5). The instrument was administered to the participants through resource persons.

\section{Validity and Reliability of Instrument}

In ensuring the validity of the instruments, the application of principal component analysis using SPSS version 21 was employed to investigate the latent factors linked to the items. The Kaiser-Mayer-Olkin and Bartletts Test of Sphericity was carried out to check the strength and sufficiency of the sample and relationship among variables. KMO is used to find out whether data are suitable for applying the factor analysis or not and explains which variable (s) should be dropped to overcome the multicollinearity problem, its ranges from 0 to 1 , where a higher value greater than 0.6 , indicates the significance of the data, and factor analysis can be employed. If its value is less than 0.60 then several items should be deleted, which are unnecessary variables based on the anti-image values. Results of KMO and Bartletts test indicate that variables are highly significant, and principal component analysis was suitable (Table: 1 ).

To ensure reliability of the instrument, the test-retest method of reliability was applied with Cronbach Alpha for each of the constructs calculated. The result gave a reliability index of (0.872) indicating a high degree of consistency (Table: 2$)$. This result shows that all the constructs are consistent and reliable to be used in this study. 
Table 1: KMO and Bartletts Test

\begin{tabular}{|l|l|l|}
\hline $\begin{array}{l}\text { Kaiser-Meyer-Olkin } \\
\text { Measure of Sampling } \\
\text { Adequacy }\end{array}$ & & .837 \\
\hline Bartletts Test of Sphericity & $\begin{array}{l}\text { Approx. Chi- } \\
\text { Square } \\
\text { Df } \\
\text { Sig. }\end{array}$ & $\begin{array}{l}78.639 \\
10 \\
100\end{array}$ \\
\hline
\end{tabular}

Source: Researchers Computation from SPSS Output, 2021

Table 2: Reliability Test Results

\begin{tabular}{|l|l|l|}
\hline Variable & Item & Cronbach's Alpha \\
\hline Knowledge Creation & 5 & 0.892 \\
\hline Knowledge acquisition & 5 & 0.874 \\
\hline Knowledge sharing & 5 & 0.844 \\
\hline Knowledge storage & 5 & 0.865 \\
\hline Organisational effectiveness & 10 & 0.823 \\
\hline Overall & 30 & 0.872 \\
\hline
\end{tabular}

Source: Researchers Computation from SPSS output, 2021.

\section{Model Specification}

This study contains the dependent and independent variables. The independent variable Knowledge management processes (KMP) comprises knowledge creation, knowledge acquisition, knowledge sharing and knowledge storage. The dependent variable is organisational effectiveness (OE)in this study is regarded as a function of knowledge management processes (KMP).

$\mathrm{OE}=\mathrm{f}(\mathrm{KMP})$

Where:

$\mathrm{OE}=$ Organisational Effectiveness (dependent variable)

$\mathrm{KMP}=$ Knowledge Management Processes (independent variable)

Given that organizational effectiveness comprises of four dimensions, the implicit form of the model is given as follows:

$\mathrm{OE}=(\mathrm{KC}, \mathrm{KA}, \mathrm{KS}, \mathrm{KA})$

Where:

$\mathrm{KC}=$ Knowledge Creation

$\mathrm{KA}=$ Knowledge Acquisition

$\mathrm{KS}=$ Knowledge Sharing

$\mathrm{KS}=$ Knowledge Storage

Thus, the explicit form of the model for the study will be as follows:

$\mathrm{OE}=\beta_{0}+\beta_{1} \mathrm{KC}+\beta_{2} \mathrm{KA}+\beta_{3} \mathrm{KS}+\beta_{4} \mathrm{KS}+\varepsilon$

Where:

$B_{0}=$ Intercept of the Model (Constant)

$\beta_{1}, \beta_{2,} \beta_{3,} \beta_{4}=$ regression coefficient

$\varepsilon=$ error term

\section{Techniques of Data Analysis}

The study applied descriptive statistics as a tool to analyze bio-data of the respondents and multiple linear regression was used to test hypothesis at 0.05 level of significance. All analyses were done through the application of the Special Package for Social Sciences (SPSS 21version). 


\section{Results and Analysis}

Data collected from the respondents were analysed using multiple linear regression and presented in tables.

\section{Regression Analysis Result}

The result of the model summary in Table 3 shows an $\mathrm{R}^{2}$ value of .681 , meaning that $68.1 \%$ of the variation in the dependent variable (organisational effectiveness) is explained by the predictor variables, while $31.9 \%$ is explained by the other variables outside the model. The $\mathrm{R}$ value of 0.882 indicates that there is a strong positive correlation between the dependent variable (organisational effectiveness) and the set of independent (knowledge creation, knowledge acquisition, knowledge sharing and knowledge storage).

Table 3: Model Summary

\begin{tabular}{|l|l|l|l|l|}
\hline $\mathbf{R}$ & R-Square & $\begin{array}{l}\text { Adjusted R } \\
\text { Square }\end{array}$ & $\begin{array}{l}\text { Std. Error of } \\
\text { The Estimate }\end{array}$ & $\begin{array}{l}\text { Durbin- } \\
\text { Watson }\end{array}$ \\
\hline $.0882^{\mathrm{a}}$ & .681 & .628 & .5822 & 1.784 \\
\hline
\end{tabular}

a. Predictors (Constant), Knowledge creation, knowledge acquisition, knowledge sharing, knowledge storage.

b. Dependent Variables: Organisational effectiveness

Source: Field Survey, 2021.

A p-value of less than 0.05 ( $p$-value $=0.000$ ) was obtained. This implies that the linear model with knowledge management processes as independent variable is significant. Therefore, as knowledge management processes are used, the effectiveness of Nigerian deposit money banks improves.

Table 4: Analysis of Variance (ANOVA)

\begin{tabular}{|l|l|l|l|l|l|}
\hline & $\begin{array}{l}\text { Sum of } \\
\text { Squares }\end{array}$ & Df & Mean Square & F & Sig. \\
\hline Regression & 32.231 & 4 & 9.228 & 40.342 & $.0000^{\mathrm{b}}$ \\
\hline Residual & 41.201 & 433 & .322 & & \\
\hline Total & 73.432 & 442 & & & \\
\hline
\end{tabular}

Dependent Variable: Organisational effectiveness

Predictors (Constant), Knowledge creation, knowledge acquisition, knowledge sharing, knowledge storing.

Source: Field Survey, 2021.

The result in the Table 5 shows that taking all other independent variables at zero, a unit increase in knowledge creation will lead to $48.2 \%$ changes in organisational effectiveness, a unit increase in knowledge acquisition will lead to $61.4 \%$ change in organisational effectiveness. Again, a unit increase in knowledge sharing will lead to $46.3 \%$ change in organisational effectiveness. Finally, a unit increase in knowledge storage will lead to a $52.2 \%$ change in organisational effectiveness.

At 5\% level of significance and 95\% level of confidence, knowledge creation showed a beta value of .323 and .000 level of significance. Knowledge acquisition showed a beta value .621 and .000 level of significance, while knowledge sharing showed a beta value of $42.4 \%$ and .000 . Knowledge sharing showed a beta value of $46.2 \%$ and .000 level 
of significance, respectively. The regression coefficient further shows that knowledge acquisition has more effect on the effectiveness of Nigerian deposit money banks. This is followed by knowledge storage, then knowledge sharing and finally, knowledge creation.

Table 5: Regression Coefficients

\begin{tabular}{|l|l|l|l|l|l|}
\hline & $\begin{array}{l}\text { Unstandardized } \\
\text { Coefficients }\end{array}$ & & & $\begin{array}{l}\text { Standardized } \\
\text { Coefficients }\end{array}$ & \\
\hline & $\mathrm{B}$ & Std Error & Beta & T & Sig. \\
\hline (Constant) & .720 & .132 & & 5.321 & .000 \\
\hline Knowledge creation & .482 & .052 & .323 & 4.688 & .000 \\
\hline $\begin{array}{l}\text { Knowledge } \\
\text { acquisition }\end{array}$ & .614 & .042 & .621 & 18.222 & .000 \\
\hline Knowledge sharing & .463 & .038 & .424 & 10.110 & .000 \\
\hline Knowledge storage & .522 & .051 & .462 & 10.222 & .000 \\
\hline
\end{tabular}

Dependent Variable: Organisational effectiveness

Source: Field Survey, 2021.

\section{Test of Hypotheses}

The following hypotheses were tested at 0.005 level of significance:

\section{Hypotheses One}

Knowledge creations have no significant effect on organisational effectiveness in Nigerian deposit money banks

The strength of the effect on organisational effectiveness in Nigerian deposit money banks measured by the calculated $p$-value $=.000$ at a significance level $(\alpha)$ of 0.05 . Since the computed $p$-value is less than the significance level $(\alpha)$ of 0.05 ( $p$-value $.000 \leq \alpha 0.05)$, the null hypotheses was rejected, and we concluded that knowledge creation have positive significant effect on the organisational effectiveness of Nigerian deposit money banks.

\section{Hypotheses Two}

Knowledge acquisitions have no significant effect on organisational effectiveness in Nigerian deposit money banks

The strength of the effect on organisational effectiveness in Nigerian deposit money banks measured by the calculated $p$-value $=.000$ at a significance level $(\alpha)$ of 0.05 . Since the computed $p$-value is less than the significance level $(\alpha)$ of 0.05 ( $p$-value $.000 \leq \alpha 0.05$ ), the null hypotheses was rejected, and we concluded that knowledge acquisition have a positive significant effect on the organisational effectiveness of Nigerian deposit money banks.

\section{Hypotheses Three}

Knowledge sharing have no significant effect on organisational effectiveness in Nigerian deposit money banks

The strength of the effect on organisational effectiveness in Nigerian deposit money banks measured by the calculated $p$-value $=.000$ at a significance level $(\alpha)$ of 0.05 . Since the computed $p$-value is less than the significance level $(\alpha)$ of 0.05 ( $p$-value $.000 \leq \alpha 0.05$ ), the null hypotheses was rejected, and we concluded that knowledge sharing have positive significant effect on the organisational effectiveness of Nigerian deposit money banks. 


\section{Hypotheses Four}

Knowledge storages have no significant effect on organisational effectiveness in Nigerian deposit money banks

The strength of the effect on organisational effectiveness in Nigerian deposit money banks measured by the calculated $p$-value $=.000$ at a significance level $(\alpha)$ of 0.05 . Since the computed $p$-value is less than the significance level $(\alpha)$ of 0.05 ( $p$-value $.000 \leq \alpha 0.05$ ), the null hypotheses was rejected, and we concluded that knowledge storage have positive significant effect on the organisational effectiveness of Nigerian deposit money banks.

\section{Discussion of Findings}

Analysis of the data collected from the researchers' field survey indicates that knowledge creation has positive significant effect on the organisational effectiveness of Nigerian deposit money banks. To confirm the findings above, regression was used to test the hypothesis at 5\% level of significance and the ( $p$-value .000) was lower than the significance level of 0.05 . This can be statistically given as $p$-value $.000 \leq \alpha 0.05$. This result was consistent with the findings of Romano et. al. (2014), Valmohammadi and Ahmadi (2015) found that knowledge creation positively and significantly affects organizational performance. Again, the result corroborated the findings of Omugbai (2021), who established that knowledge creation significantly affects organisational performance of the Nigerian banking industry.

Findings of the study on hypothesis two also indicated that knowledge acquisition has a positive significant effect on organisational effectiveness in Nigerian deposit money banks. To affirm the findings above, regression was used to test the hypothesis at $5 \%$ level of significance and the (p-value .000) was lower than the significance level of 0.05 . This can be statistically given as $p$-value $.000 \leq \alpha 0.05$. Although Martin (2012) examined the knowledge acquisition strategies and company performance in Young High Technology Company in Germany, making use of quantitative and qualitative data. The study reveals four distinct knowledge acquisition strategies (low-key, mid-range, focus and explorer) and shows that strategies differ in their relation to company performance because of their configuration of knowledge acquisition activities and the type of knowledge acquired. This result was consistent with the findings of Rasula et.al. (2012) and Nnabuife et al. (2015) who established a positive significant effect of knowledge acquisition on organisational performance and administrative employees in educational institutions in Nigeria. However, Ahmad, Mohamad, and Ibrahim (2013), found that individual absorptive capacity has partial influence on employee's knowledge acquisition.

Findings of the hypothesis three also reported a positive significant effect between knowledge sharing and organisational effectiveness in Nigerian deposit money banks. To acknowledge the findings above, regression was used to test the hypothesis at $5 \%$ level of significance and the ( $p$-value .000) was lower than the significance level of 0.05 . This can be statistically given as p-value $.000 \leq \alpha 0.05$. Stefanescus and Stefanescus (2008) discussed the factors that motivate in sharing knowledge before implementing any KM strategy to sustain the successful implementation of reengineering projects. The study concluded that to achieve success with reengineering projects, organisations should possess and share knowledge about many different facets of this process; and that improvement of performance of engineering projects comes because of coupling IT capabilities with KM strategy. The finding agrees with Mohamad, et al. (2013) that investigated the influence of 
knowledge management practices on organisational performance in small and medium enterprises (SMEs) in Iran, using structural equation modeling (SEM). The finding showed that knowledge acquisition, storage, creation, and implementation have a significant factor loading on knowledge management; and, productivity, financial performance, staff performance, innovation, work relationships, and customer satisfaction have significant factor loading on organisational performance. Ode (2021) has affirmed that knowledge sharing strategy demonstrated the highest positive significant effect on firm innovation through knowledge application strategy.

On knowledge storage, the findings indicated a positive significant effect between knowledge storage and organisational effectiveness in Nigerian money deposit banks. To substantiate that, regression was used to test the hypothesis at $5 \%$ level of significance and the ( $p$-value .000) was lower than the significance level of 0.05 . This can be statistically given as $p$-value $.000 \leq \alpha 0.05$. Ode (2021) has affirmed that knowledge storage strategy demonstrated a positive significant effect on firm innovation through knowledge application strategy. To envelope that the findings of Omugbai (2021) established that knowledge storage positively and significantly affects organisational performance of the Nigerian banking industry which is in consonance with the current study.

\section{Conclusions}

Like every study, there are conclusions, recommendations and limitations that could be drawn from the findings of the research. Findings from this study indicates that knowledge management processes affect organisational effectiveness. Specifically, this study concludes that knowledge creation, acquisition, sharing, and storage have a positive significant effect on organisational effectiveness in Nigerian deposit money banks. This study contributes to the existing literature on knowledge management processes and organisational effectiveness by proposing a model that demonstrate how knowledge creation, acquisition, sharing, and storage affects organisational effectiveness in Nigerian deposit money banks. In terms of practical application of the findings, the findings reveal how money deposit banks in developing countries can improve their effectiveness through different knowledge management processes.

\section{Research limitations and Directions for Further Studies}

There are some limitations associated with this research. This study derives from a selfreported data obtained from managers of selected deposit money banks in Nigeria. This can potentially lead to common method bias. Secondly, this study recognizes the multidimensional nature of knowledge management. This study focused on four processes knowledge management, namely creation, acquisition, sharing and storage. The literature has identified several other knowledge management processes that are not captured in this study. These processes are equally useful and deserves attention. Thirdly, a cross-sectional approach was used. This approach does not capture the long-term nuances and mechanisms that interact to influence organisational effectiveness. Finally, this study was limited to four deposit money banks with headquarters in Lagos state, Nigeria. It is therefore suggested that further studies should be carried out to cover other deposit money banks in Nigeria. Further studies should implement a research design to the extent of having interview with more banks, to investigate further what triggers banks to adopt knowledge management processes in their operations and not just based on the questionnaire survey as it is not sufficient. Finally, other researchers could investigate on challenges of knowledge 
management processes in the Nigerian deposit money banks in their industry and other sectors in Nigeria. Again, future studies can adopt a longitudinal approach to examine the long-term effect of knowledge management processes and how these processes evolve over time. The findings from this study shows that knowledge acquisition is very relevant to organisational effectiveness. Future studies can isolate knowledge acquisition as a process and examine how knowledge can be acquired within organizations in different sectors. Regardless of the stated limitations, this study provides a useful framework to explain how different knowledge management processes interact to enhance organisational effectiveness.

\section{Recommendations}

Management of Nigerian deposit money banks should aptly design and encourage knowledge creation in their banks since it constitutes a valuable intangible asset for creating and sustaining exceptional competitive advantages in the Nigerian banking industry.

Since knowledge management is an important aspect in every organization and the practice of capturing and developing individual and collective knowledge in organizations, management of Nigerian deposit money banks are encouraged to seek and implementing knowledge management enables the organization in becoming more flexible and better at responding to intense global competition which will eventually lead to profit maximisation hence organisational effectiveness.

Management of Nigerian deposit money banks should always encourage knowledge sharing in their banks. This is important because knowledge sharing helps individuals and businesses to be more agile and adaptable in the face of change and helps ensure continued organisational growth and survival.

Knowledge can be stored and later retrieved which is also called organisational memory and includes knowledge that employees recall as well as knowledge embedded in the organisations systems and structures. One of the ways of retaining the organizations memory is motivating employees to remain with the company in which they are committed to. Management of deposit money banks are to provide an enabling environment that knowledge can be stored and retrieved when needed in for effective operations within their domain.

\section{References}

Abubakar A. M., Elrehail H., Alatailat M. A., \& Elçi A. (2019). Knowledge management, decision-making style, and organizational performance. Journal of Innovation and Knowledge 4. 104-114.

Abusweilem, M \& Abualoush, S. (2019). The impact of knowledge management process and business intelligence on organizational performance. Management Science Letters, 9(12), 2143-2156.

Addicot, R; McGivern, G; \& Ferlie, E (2006). "Networks, Organizational Learning and Knowledge Management: NHS Cancer Networks". Public Money \& Management. 26(2): 87-94.

Adudu, C.A; Asenge, E.L \& Torough, S.M (2020). Outsourcing Strategies and Organizational Performance of Deposits Money Banks (DMBs) in Nigeria. Global Scientific Journal, 8(3) pp 2484-2505. 
Ahmed, F., Mohamed, O. \& Ibrahim, I. (2013). Knowledge Acquisition among Engineering in MNCs. Independent Journal of Management and Production, 4(1).

Amah, E (2006). Human resources management. Port-Harcourt: Amethyst.

Alavi, M.; \& Leidner, D.E. (2001). "Review: Knowledge Management and Knowledge Management Systems" (PDF). MIS Quarterly. 25(1): 107-136.

Al-Emrana, M; Mezhuyev, V; Kamaludin, A \& Shaalan, K (2018)The impact of knowledge management processes on information systems: A systematic review: International Journal of Information Management, 43. Pp 173-187

Ali A. A., Paris L., \& Gunasekaran A. (2019). Key factors influencing knowledge sharing practices and its relationship with organizational performance within the oil and gas industry. Journal Knowledge Management. 23 1806-1837. 10.1108/jkm-06-20180394

Ali, S. I., Yousof, J. Khan, M. R \& Masood, A.S. (2011). Evaluation of performance in manufacturing organization through productivity and quality: African Journal off Business Management: Retrieved December22,2018fromhttp:/www.academicjournal.org/AJBM.

Ang, Z., \& Massingham, P. (2007). National culture and the standardization versus adaptation of knowledge management. Journal of Knowledge Management, 11(2), $5-21$.

Balasubramanian, S., Al-Ahbabi, S. \& Sreejith, S. (2019). Knowledge management processes and performance: The impact of ownership of public sector organizations: International Journal of Public Sector Management. 33(1).

Barney, J. (1991). Firm resources and Sustained Competitive Advantage. Journal of Management, 17. PP.99-120.

Bennet, D \& Bennet, A. (2001). The rise of the knowledge organization: The catalyst for election In Management Concepts. 4(2) pP.6-18.

Bhagavath, V. (2009). Technical efficiency measurement by data envelopment analysis: An application in Transportation Model, Alliance Journal of Business research, 8(3):56-69.

Biemer, L \& Lyberg, L (2003). Introduction to Survey Quality Hoboken, NJ: John Wiley \& Sons

Byukusenge, E., Munene, J. \& Orobia, L (2016). Knowledge Management and Business Performance: Mediating Effect of Innovation: Journal of Business and Management Sciences. 4(4) 2016, pp 82-92.

Cai, L; Sheikh, F. A; Fakhar S; Iram, B; Majid, M; Nausheen, S. \& Madiha R(2021), influence of knowledge management practices on entrepreneurial and organizational performance: A mediated-moderation model: Front Psychol. 2020; 11: 577106. Published online 2020 Dec 3.

Cardoni, A.; Zanin, F.; Corazza, G.; \& Paradisi, A. (2020). Knowledge Management and Performance Measurement Systems for SMEs' Economic Sustainability. Sustainability 2020, 12, 2594.

Conner, K.R. (1991). A Historical Comparison of the Resource-Based Theory and Five Schools of Thought Within Industrial Organization Economics: Do We Have a New Theory of the Firm?". Journal of Management. 17 (1): 121-154.

Drucker, P. (2001). The coming of the new organization, In Harvard Business Review. 
Erkuttu, H. V.\& Chafra, J. (2006). Relationship Between Leadership power bases and Job Stress of Subordinates: Example from Boutique Hotels. Management Research News, 29 (5): 285-297.

Forouzan, R; Mohammad, K \& Paria S (2021) Factors Affecting Knowledge Management and Its Effect on Organizational Performance: Mediating the Role of Human Capital, Advances in Human-Computer Interaction, pp. 1-16.

Girard, J. P. \& Girard, J. L. (2015) Defining knowledge management: Toward an applied compendium" (PDF). Online Journal of Applied Knowledge Management. 3(1): 14.

Gupta, J; \& Sharma, S. (2004). Creating Knowledge Based Organizations. Boston: Idea Group Publishing.

Ha S. T \& Lo M. C. (2018). An empirical examination of knowledge management and organizational performance among Malaysian manufacturing SMEs. International Journal of Business Innovation Research. 17. pp. 23-37.

Heisig P (2009). Harmonization of Knowledge Management comparison of 160 framework: Journal of Knowledge Management, 13(4): pp. 4-31.

Hossain, M. S., Islam, M. A., \& Haque, A. A. (2021) Empirical analysis to the factors impact on succession process of the family-owned businesses in Bangladesh, moderating role of education. International Journal of Business Innovation and Research 24(4) pp. 1-18.

Iacobucci, D. (2010). Structural equations modelling: Fit Indices, sample size, and advanced topics. Journal of Consumer Psychology, 20(1) pp. 90-98.

Ikenwe \& Igbinovia (2016). Influence of knowledge sharing in reducing the spread of Information Management, 28(1), pp.131-159.

Islam, M. A., Jantan, A. H., Khan, A. M., Rahman, M. H., \& Monshi, O. (2018). Impact of motivational factors on knowledge sharing behaviour of managers in Ready Made Garments (RMG) Industry of Bangladesh. Journal of Business and Retail Management Research, 13(1), pp. 179-189.

Jain, V.K. (2017). A study of organizational effectiveness variables in Indian Industry. International Journal of Current Research. 4(2) pp. 51.69.

Kalluru, S. \& Bhat, K. (2009). Determinants of Cost Efficiency of Commercial banks in India. ICFAI Journal of Bank Management, 8(2) pp. 32-50.

Kamaga, F. N \& Ismail, N. S. (2016) Effects of Outsourcing on Organization Performance in Manufacturing in Kenya: A case of Del Monte Kenya Limited: European Journal of Logistics, Purchasing and supply Chain Management, 4(3) pp. 32-58.

Kharabsheh, R., Magableh, I., \& Sawadha, S. (2012). Knowledge management practices and its impact on organizational performance in pharmaceutical firms. European Journal of Economics, Finance and Administrative Sciences, 48, 6-15.

Kimiz, D. (2005). Knowledge Management in Theory and Practice: Elsevier Butterworth Heinemann publications

King, W. R (ed.), Knowledge Management and Organizational Learning, 3Annals of Information Systems 4, DOI 10.1007/978-1-4419-0011-1_1, C Springer Science Business Media, LLC 2009.

Krejcie, R.V., \& Morgan, D.W., (1970). Determining Sample Size for Research Activities. Educational and Psychological Measurement.

Liebowitz, J. (1999). Knowledge management handbook. CRC press.

Maier, R. (2007). Knowledge Management Systems: Information and Communication Technologies for Knowledge Management (3rd ed.). Berlin: Springer. 
Martin, F. (2012). Knowledge Acquisition Strategies and Company Performance in Young High Technology Companies. British Journal of Management, 23, 325-343.

Martz, W. (2013). Organizational effectiveness checklist. Dissertation Abstract International, 78(12),53-65.

Meyer, J. P.; \& Allen, N. J. (1991). A three-component conceptualization of organizational commitment. Human Resource Management Review. 1: 61-89.

Mohamed, H., Mehrdad, N. Salman, M \& Noruzy, A. (2013). Investigating the Influence of Knowledge Management Practices on Organizational Performance: An Empirical Study. Acta Polytechnia hungarica, 10(2).

Mutula, SM, \& Mooko, NP (2008) Knowledge management. In: Aina, L.O., Mutula, S.M., Tiamiyu, M.A. (eds) Information and Knowledge Management in the Digital Age: Concepts, Technologies, and African Perspectives. Third World Information Services Limited, Ibadan, Nigeria.

Nayak, B., \& Misha, B.B. (2005). Impact of leadership style on organizational effectiveness. Journal Management and Labor Studies, 30(1) 90-92.

Ndolo, P. A. (2015) The Relationship Between Operational Efficiency and Financial Performance of Firms listed at the Nairobi Securities Exchange: School of Business, University of Nairobi, MSc Finance.

Nnabuife, E. K. Onwuka, E. M \& Ojukwu, H.S (2015). Knowledge Management and Organizational Performance in Selected Commercial Banks in Awka, Anambra State, Nigeria: Journal of Business and Management, 17(8) PP 25-32.

Nonak, I., \& Takeuchi, H. (1995). The knowledge creating company. New York: Oxford Press.

Nonaka, I. (1994). A dynamic theory of organizational knowledge creation. Organization Science, 5(1), 14-37.

Nonaka, I., \& Von Krogh, G. (2009). Perspective Tacit knowledge and knowledge conversion: Controversy and advancement in organizational knowledge creation theory. Organization science, 20(3), 635-652.

Nurul-Huda, B. M. (2007). Knowledge management in manufacturing industry. Retrieved from

http://library.utem.edu.my/index2.php?option=com_docman\&task=doc_view\&gid $=3508$ \&Itemid $=342$

Ode, E (2021). The Effect of Knowledge Management Strategies on firm innovation: An Analysis of Service Firms in Nigeria. Mkar Journal of Management and Social Sciences: 4(1) pp 177-190

Rafique M., Hameed S., Agha M. H. (2018). Impact of knowledge sharing, learning adaptability and organizational commitment on absorptive capacity in pharmaceutical firms based in Pakistan. Journal of Knowledge Management 2244 56.

Rasula, J., Vuksic, V.B., and Stemberger, M.I., (2012). The impact of knowledge management on organizational performance. Economics and Business Review, 14(2), pp.147-160.

Richard, P. Devinney, M. George, Y.S. and Johnson. G. (2009). Measuring organizational Performance: towards methodological best practices. Journal of Management, 35(3): 718- 804. 
Romano, M., Del Giudice, M. and Nicotra, M. (2014), "Knowledge creation and exploitation in Italian universities: the role of internal policies for patent activity", Journal of Knowledge Management, 18(5), pp. 952-970.

Russell, S \& Norvig, P. (1995). Artificial Intelligence: A Modern Approach (PDF). Simon \& Schuster. pp. 22-23.

Samir, M. (2020) The Impact of Knowledge Management on SMEs Performance in Egypt. Open Access Library Journal, 7, 1-23.

Sanchez, R. (1996). Strategic Learning and Knowledge Management. Chichester: Wiley.

Santoro G., Vrontis D., Thrassou A., \& Dezi L. (2018). The internet of things: building a knowledge management system for open innovation and knowledge management capacity. Technology Forecast Social Change, 136. 347-354.

Stefanescus, L. \& Stefanescus, A., (2008). The need of knowledge management strategy for the successful implementation of reengineering projects: Journal of Knowledge Management, 6(6), pp.51-60.

Suhaida, B. A. K. (2012). A review on the models of organizational effectiveness: a look at Camerons model in higher education. International Education Studies, 5(2), 80-87.

Umogbai, M. E (2021). Knowledge management and organizational performance in the Nigerian banking industry. Mkar Journal of Management and Social Sciences: 4(1) pp155-164

Valmohammadi, C.\& Ahmadi, M. (2015). The impact of knowledge management practices on organizational performance: A balanced scorecard approach. Journal of Enterprise Information Management, 28(1), 131-159.

Witek-Crabb, A (2014). Business growth versus organizational development reflected in the strategic management of Polish small, medium, and large enterprises. Journal of Social and Behavioural Sciences. Vol. 5(3) pp 66-76.

Wu, C. C., Wu, C. H., Li, C. C., \& Huang, T. H. (2011). Drivers of organizational knowledge management. African Journal of Business Management. 5(11), 43-88.

Zaim, H. Mohammed, S \& Tarim, M. (2018). Relationship between knowledge management processes and performance: critical role of knowledge utilization in organizations: Knowledge Management Research \& Practice. 17(1).

Zheng, W. (2005). The Impact of organizational culture, structure, and strategy on knowledge management effectiveness and organizational effectiveness (Doctoral dissertation, University of Minnesota).

Zook, G. A. (2015). Leadership understandings of organizational effectiveness: An exploration within the context of faith-based international nongovernment organizations (Doctoral dissertation, Eastern University). 